\title{
Can Blackcurrant (Ribes Nigrum L) Help in Control of Ligneous Conjunctivitis?
}

\author{
Mariana Granito Ponte de Oliveira* \\ Department of ophthalmology, Spain \\ *Corresponding author: Mariana Granito Ponte de Oliveira, Department of ophthalmology, Spain.
}

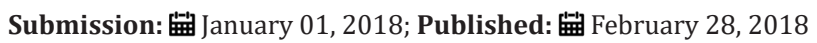

\section{Opinion}

Plasminogen is an enzyme that is linked to the dissolution of fibrin, and consequently thrombi. It plays an important role in the recruitment of macrophages during the inflammatory response. Plasminogen deficiency is a rare autosomal recessive disease, which may be heterozygotes asymptomatic or homozygou symptomatics. It can be correlated to appearance of low levels of plasminogen in children, whose both parents have reduced values [1].

The ligneous Conjunctivitis (LC) is the most common presentation of clinical syndromes associated with type I plasminogen deficiency [2,3]. It's a rare pathology and may be more prevalent in areas where consanguinity is more common $[1,3]$. Its diagnosis is based on clinical, histological and possibly positive family history. Clinical findings are usually: Chronic tearing, conjunctival hyperemia, pseudomembranous lesion in the conjunctiva and/or other mucosal sites of the body, possibly associated with colloid milium or obstructive congenital hydrocephalus. Such membranes are deeply adhered to the conjunctiva of the eyelid, with its free end. Removal tends to cause bleeding because the area is vascularized $[4,5]$.

It is possible to verify the presence of mast cells and eosinophils in the lesions, which leads to believe that the deposition of the secretions would be by degranulation of these mast cells. It is also understood that massive extravasation of plasma constituents, fibrin in particular that end up forming a kind of granulous lesion $[4,6]$. A Ribes nigrum L. (Glossulariaceae), popularly known as blackcurrant, is a plant known to be a source of highly antioxidant gamolinic acid $[7,8]$. The literature shows that it has anticoagulant effect by being able to inhibit the formation of fibrin [7].

Granito \& Ferreira [5] shown a case study, with a Patient C.G.C.P., 13 years old, "female, diagnosed at 3 years old with ligneous conjunctivitis due to a symptomatic homozygous deficiency of plasminogen (Functional Plasminogen 20\%; Reference threshold according to the medical diagnostic laboratory: $70 \%$ to $140 \%$ ). Concomitant to the disease, the same featured low immunity with frequent appearance of skin infections due to atopic dermatitis, and in the respiratory tract, constant rashes, and excessive production of secretions in the mucosa of the eyelid, with growth of ligneous pseudo membrane (PL). Since the beginning of the lesions, around
2 years of age, the same underwent surgical procedures several times for the removal of the PL, which were recurrent weeks after removal. This process was carried out as reported in the present study, without the use of the specific medication described. She only used anesthetic eye drops in the post-operative period, and topical use of loteprednol elaborate ( $2 \mathrm{mg}$ applied $3 \mathrm{x} /$ day). The treatment with about $1 \mathrm{~g} /$ day of calf thymus acid lysate was carried out, equivalent to $20 \mathrm{mg}$ of the active ingredient thymomodulin in an attempt to improve the immune system without great results" But, the patient cessed the nutritional treatment [5] and mucus production increased, as well as the level of growth of PL. So, a therapy with $500 \mathrm{mg} /$ day of Ribes nigrum seed oil was started with this same patient two years later.

After 2 moths of treatment, there was a significant improvement in the production of mucus in the eyes and PL had a soft texture, easy to remove, often releasing small pieces after hot water massage (in the bath). It is therefore suggested that this therapy may present important results, therefore, larger studies are recommended.

\section{References}

1. Cohen J, Cohen S, Cymberknoh MC, Gross M, Hirshoren N, et al. (2012) Laryngeal obstruction in congenital plasminogen deficiency. Pediatr Pulmonol 47(9): 923-925.

2. Kraft J, Lieb W, Zeitler P, Schuster V (2000) Ligneous conjunctivitis in a girl with severe type I plasminogen deficiency. Graefes Arch Clin Exp Ophthalmol 238(9): 797-800.

3. Mehta R, Shapiro AD (2008) Plasminogen deficiency. Haemophilia 14(6): 261-1268.

4. Holland EJ, Schwartz GS (1997) Ligneous conjunctivis. In: Krachmer JH \& Mannis MJ (Eds.), Cornea and extrenal disease: clinical diagnosis and management. Cornea pp. 863-889.

5. Granito M, Ferreira JM (2016) Nutritional treatment for leagnous conjuntivitis: case report and literature review and case report. Rev Bras Oftalmol 75(6): 476-480.

6. Schuster V, Seregard S (2003) Ligneous conjunctivitis. Surv Ophthalmol 48(4): 369-388.

7. Goffman FD, Galletti S (2001) Gamma-linolenic acid and tocopherol contents in the seed oil of 47 accessions from several Ribes species. Journal of Agricultural and Food Chemistry 49(1): 349-354.

8. Cord D, Popescu M, Hobeanu I, Sandulovici RC, Raiciu AD (2017) Efectul antiinflamator al speciei Ribes nigrum. Romanian Journal of Medical Practice 12(2): 97-103. 


\section{Your subsequent submission with Crimson Publishers} will attain the below benefits

- High-level peer review and editorial services

- Freely accessible online immediately upon publication

- Authors retain the copyright to their work

- Licensing it under a Creative Commons license

- Visibility through different online platforms

- Global attainment for your research

- Article availability in different formats (Pdf, E-pub, Full Text)

- Endless customer service

- Reasonable Membership services

- Reprints availability upon request

- One step article tracking system 